\title{
Overstraining international climate finance: when conflicts of objectives threaten its success
}

\author{
Wolfgang Buchholz
}

Department of Economics, University of Regensburg, Regensburg, Germany and CESifo, Munich, Germany, and

Dirk Rübbelke

Faculty of Business Administration, Technische Universität Bergakademie

Freiberg, Freiberg, Germany and Center for Environmental Management, Resources and Energy, Faculty of Management and Economics, Ruhr Universität Bochum, Bochum, Germany

\begin{abstract}
Purpose - Climate finance is regularly not only seen as a tool to efficiently combat global warming but also to solve development problems in the recipient countries and to support the attainment of sustainable development goals. Thereby, conflicts between distributive and allocative objectives arise, which threaten the overall performance of such transfer schemes. Given the severity of the climate change problem, this study aims to raise concerns about whether the world can afford climate transfer schemes that do not focus on prevention of (and adaptation to) climate change but might be considered as a vehicle of rent-seeking by many agents.

Design/methodology/approach - Future designs of international transfer schemes within the framework of the Paris Agreement are to be based on experience gained from existing mechanisms. Therefore, the authors examine different existing schemes using a graphical technique first proposed by David Pearce and describe the conflicts between allocative and distributional goals that arise.

Findings - In line with the famous Tinbergen rule, the authors argue that other sustainability problems and issues of global fairness should not be primarily addressed by climate finance but should be mainly tackled by other means.

Research limitations/implications - As there is still ongoing, intense discussion about how the international transfer schemes addressed in Article 6 of the Paris Agreement should be designed, the research will help to sort some of the key arguments.

Practical implications - There are prominent international documents (like the Paris Agreement and the UN 2030 Agenda for Sustainable Development) seeking to address different goals simultaneously. While synergies between policies is desirable, there are major challenges for policy coordination. Addressing several different goals using fewer policy instruments, for example, will not succeed as the Tinbergen Rule points out. Social implications - The integration of co-benefits in the analysis allows for taking into account the social effects of climate policy. As the authors argue, climate finance approaches could become overstrained if policymakers would consider them as tools to also solve local sustainability problems.
\end{abstract}

(C) Wolfgang Buchholz and Dirk Rübbelke. Published by Emerald Publishing Limited. This article is published under the Creative Commons Attribution (CC BY 4.0) licence. Anyone may reproduce, distribute, translate and create derivative works of this article (for both commercial and noncommercial purposes), subject to full attribution to the original publication and authors. The full terms of this licence may be seen at http://creativecommons.org/licences/by/4.0/legalcode JEL classification - H41, H87, Q54, Q56
International climate finance

Received 26 June 2021 Revised 8 August 2021 10 September 2021 Accepted 11 September 2021 
IJCCSM

$13,4 / 5$

Originality/value - In this paper, the authors will not only examine what can be learnt from the clean development mechanism (CDM) for future schemes under Article 6 of the Paris Agreement but also observe the experiences gained from a non-CDM scheme. So the authors pay attention to the Trust Fund of the Global Environment Facility (GEF) which was established with global benefit orientation, i.e. - unlike the CDM - it was not regarded as an additional goal to support local sustainable development. Yet, despite its disregard of local co-benefits, the authors think that it is of particular importance to include the GEF in the analysis, as some important lessons can be learnt from it.

Keywords Ancillary benefits, CDM, Climate finance, Co-benefits, Global environment facility,

Incremental cost, International transfers, Paris agreement, Premium prices,

Sustainable development goals, CDM and premium prices

Paper type Research paper

\section{Introduction}

Recent efforts in the industrialized world to improve climate protection, like the Green Deal of the European Union or the German $\$ 60 \mathrm{bn}$ Climate Package, raised some concern about the efficiency of climate policy on the global scale. As long as there are cheaper climatechange mitigation options in developing countries, it can be considered as counterproductive to spend money for reinforced abatement in industrialized countries as spending a dollar on greenhouse gas abatement in developing countries will bring about more of the urgently needed climate protection than spending this dollar in the industrialized world. As global warming is threatening life on earth, a waste of resources should be prevented, and thus international cooperative approaches aiming at using transfers to steer abatement activities to places where abatement is cheapest should get particular weight. This is an efficiency argument in favour of international transfers to improve climate protection at a global scale, and thus of global "climate finance" (on different concepts of climate finance see, e.g. Markandya et al., 2017).

Yet, beyond the efficiency goal, there are arguments that tarnish the picture. On the one hand, there is some ethical concern that developed countries will consider climate transfers as a modern form of indulgence trading. On the other hand, there is a concern that developing countries may want to misuse such transfers as an instrument for rent-seeking, i.e. for increasing the amount of development aid flowing to them. Nevertheless, a fair assessment of climate transfers requires to take "other benefits" for developing countries into account, which, e.g. result from attaining social development goals SDGs. While the benefits from slowing or combatting global warming are considered as the "primary benefits" (Buchholz et al., 2020) all "other benefits" from climate change mitigation measures are called "ancillary benefits" or "co-benefits". These terms will be used interchangeably in this paper. While the primary effects are globally public, the ancillary effects are regularly private from the point of view of a mitigation project's host country. Therefore, the recipient of climate transfers that hosts mitigation projects will enjoy these additional benefits, through which a redistribution from developed to developing countries is brought about. Frequently, these local benefits are subsumed under the term "sustainable development benefits". The transfer-induced "export" of climate protection improves the prospects for attaining sustainable development goals (SDGs) in developing countries. The positive distributional effect, which thus arises for developing countries e.g. from the improvement of local air quality, tends to be important (West et al., 2013). In their survey of studies concerning air-quality-related ancillary benefits, Nemet et al. (2010) report that these cobenefits are of a similar order of magnitude as greenhouse gas abatement costs.

Developing countries prefer those with a high degree of "ancillary" sustainable development (SD) benefits, while transfer-paying developed countries those with a high 
climate protection impact. Hence, a conflict of interest arises and efficiency in global climate protection may be impaired if activities are preferred that bring about high co-benefits but at the same time less climate protection. In this context, it also matters how exactly it can be determined whether a project that is supported through climate finance really is additional.

Against the background of this tension, the important task is to implement provisions for climate transfers in a way that respects both the efficiency and distributional concerns.

In the Paris Agreement, Article 6 addresses international cooperative approaches being related to climate finance like the successor of the clean development mechanism (CDM). The practical implications of Article 6, however, are not yet operational, giving the opportunity to take into account lessons learned in the past. So according to $\S 37$ of Decision 1/CP.21 adopted by the Conference of the Parties in Paris 2015 future designs of climate transfer schemes should be based on experience gained from existing mechanisms. Therefore, the key research questions of this paper are:

$R Q 1$. What can we learn from experiences made with earlier instruments especially in their handling of co-effects?

$R Q 2$. How can this assessment be used for improving the design of future schemes envisaged by the Paris Agreement?

Most of the research on earlier instruments of climate finance has been focused on the CDM, which already pursues both climate protection and (local) SD (Shrivastava and Bhaduri, 2019), Michaelowa et al. (2020a), Michaelowa et al. (2020a, 2020b) and Ugochukwu (2020). Some studies especially consider the experience gained in individual countries (Rive and Rübbelke, 2010; Mori-Clement, 2019; Góes et al., 2021; Stahlke et al., 2021), while other studies more generally link the co-effects of the CDM with the SDGs (Campagnolo and de Cian, 2020). A few papers as, e.g. Lang et al. (2019) address climate finance schemes that are distinct from the CDM like voluntary carbon offsets.

In this paper, the authors will not only examine (to address RQ1) the CDM but also observe the experiences made with a non-CDM scheme, i.e. the Trust Fund of the Global Environment Facility (GEF), which had a completely global orientation and was not regarded as an instrument to support local SD. Notwithstanding that, the GEF is included in the analysis, as some important lessons can be learnt from it, e.g. with respect to the handling transaction cost.

Experiences with CDM and GEF complement each other in the learning process just because the underlying conceptions are very distinct. It will be examined how the schemes have dealt with co-benefits and the associated advantages for developing countries. Weaknesses and strengths of the different instruments are described and it will be explored how the schemes have handled the trade-offs between different policy objectives and conflicts of interest between transfer payers and recipients.

To provide a theoretical foundation for this assessment, a graphical method is used that has been proposed by Pearce (2007) in the tradition of the Coasean bargaining approach. With this model, the cost-effectiveness of different transfer schemes and their influence on global welfare and the rents of transfer payers and recipients can easily be examined.

To learn how the assessment of the different schemes can be used for improving the design of future schemes envisaged by the Paris Agreement (RQ2), particular attention is paid to the schemes' contributions to both efficiency and distributional goals. Concerning efficiency, we will draw on the general theoretical insight that pursuing two different objectives with one policy instrument raises a basic problem: The famous Tinbergen Rule 
IJCCSM

$13,4 / 5$

states that for an effective policy at least $n$ independent policy instruments are required to successfully reach $n$ independent policy targets. Hence, one has to ask whether it makes sense at all to address primary and ancillary benefits by the same instrument or whether different instruments are needed that have to be coordinated in a sensible way.

The paper is organised as follows: In Section 2, we consider how the GEF Trust Fund has handled different benefit components in its system of disbursing funds towards the developing world and we assess how the different features of the GEF have influenced (e.g. via transaction costs) efficiency and distribution. Then, in Section 3, we turn to the CDM scheme where we in particular examine the effects of a "premium system", which requires a minimum level of local sustainability co-benefits. These effects are then contrasted with those identified for the GEF schemes before. In Section 4, we compare the discussed schemes with respect to the various evaluation criteria that are of importance for allocation and distribution. Emphasizing the strengths and weaknesses of the schemes may improve the design of new schemes and support decision-making under Article 6 of the Paris Agreement. Section 5 concludes.

\section{The Global Environment Facility and co-benefits}

The GEF was established as an international financial mechanism to tackle global environmental problems in 1992. Initially, it concentrated on the four focal areas climate change, biodiversity, ozone depletion and international waters [1]. The World Bank, the United Nations Development Programme and the United Nations Environment Programme were chosen as the implementing agencies during the Facility's early years. As Kaul and Conceição (2006, p. 39) point out, "[t]he Global Environment Facility is a precursor of today's emerging carbon markets" because it "facilitates trade between countries in the inputs to [...] global public goods".

In the context of climate change, Article 4 of the UN Framework Convention on Climate Change was of particular importance for the GEF. In this Article, it is stated that the developed country Parties and other Parties included in Annex II shall provide financial resources, "needed by the developing countries to meet the agreed full incremental costs" of - among other things climate change mitigation undertaken by developing countries. In line with the provisions of Article 4, the GEF's available funds are provided by developed countries and the Facility channels these funds towards developing countries to support projects and measures reducing greenhouse gas emissions. In this regard, financing "incremental cost" means covering the extra expense incurred by incremental activities of developing countries benefiting the global environment. Incremental activities are those actions of developing countries that would not have occurred without the support of the GEF. Put it differently, to identify incremental activity one distinguishes between two policy scenarios, i.e. between the "business-as-usual" (GEF, 2007) climate policy scenario without assistance by the GEF in a developing country and the scenario where the Facility's support has modified the climate protection efforts in this country. Thus, the activities above and beyond the "business-as-usual" (or baseline) are "incremental".

Meanwhile, the GEF is not only entrusted with the operation of the Financial Mechanism of the Convention but also administers the "Least Developed Countries Fund", the "Special Climate Change Fund" and provides secretariat services to the "Adaptation Fund" (IISD, 2019). Furthermore, it also serves as part of the financial mechanism of the Paris Agreement as was agreed at the COP 21 in Paris in 2015. The Paris Agreement requested the GEF to support the establishment of the capacity-building "Initiative for Transparency", for example, which seeks to strengthen the institutional and technical capacities of non-Annex I countries to meet the transparency requirements defined in Article 13 of the Paris Agreement. 
Although the implementation of the GEF Trust Fund was initially driven with global-benefit-orientation [2], the GEF accepted already in its pilot phase (June 1991 to mid-1994) "that the local/global benefits distinction would be blurred in many cases" (Pearce, 1995, p. 143). A key principle of the GEF is to aim at the cost-effectiveness of greenhouse gas abatement. Thus, the money of the GEF Trust Fund is to be disbursed in a way that for given funds secures a maximum of global benefits.

In the early years of the GEF Trust Fund, there was an intense discussion not only about the correct determination of the "business-as-usual" (or baseline) but also about the appropriate level of transfers when supported projects are jointly producing global and local benefits. For such cases, which tend to be the rule and not the exception, two polar financing concepts were discussed, i.e. the financing of net incremental cost (NIC) and of gross incremental cost (GIC). The NIC and GIC stand for the lower and upper bounds of the agreed full incremental cost that are to be reimbursed (Pearce, 1995, pp. 168-170).

While the GIC concept does not offset the costs of incremental activities with the domestic co-benefits or ancillary benefits of these GEF-supported activities in developing countries, the NIC concept nets out domestic benefits in the shape of ancillary benefits and direct economic benefits, e.g. derived by the host country from saved energy expenses. Thus, the international NIC-based compensations are lower than those associated with the GIC concept and the principle of cost-effectiveness pursued by the GEF suggests the application of the NIC concept. In line with this, King (2006) argues that consideration of domestic, as well as global benefits "is important because international compensation for incremental cost should be provided net of the domestic benefits."

To explain the differences between NIC and GIC in Figure 1 below we use a graphical method that has been suggested by Pearce (2007) to investigate GEF transfers. The method rests on the observation that there is a parallel between the GEF scheme and Coasean bargaining (Coase, 1960) under the "beneficiary-pays" principle. The GEF bargains with

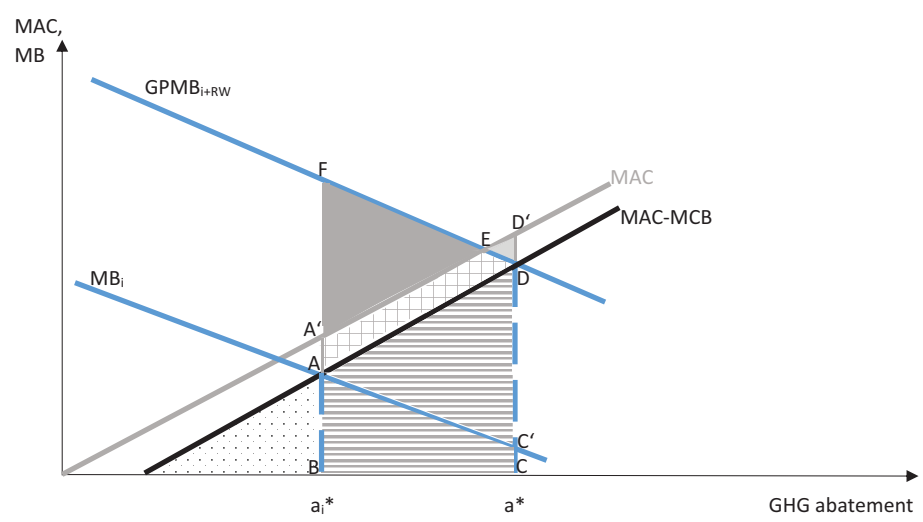

Notes: MBi: marginal benefit for country i from climate change mitigation, GPMBipRW: global public marginal benefits of mitigation, MAC: gross marginal abatement costs in country i, MCB: domestic marginal co-benefits in country i, MAC-MCB: net marginal abatement costs in country $i$

Figure 1. Illustration of GIC and NIC schemes 
IJCCSM

$13,4 / 5$

developing countries to reduce their emissions (Fankhauser and Pearce, 2014). As Pearce (2004, pp. 138-139) puts it:

Developing countries have sovereign rights to use their natural resources as they see fit, but the world as a whole has an interest in and would benefit from, their conservation.

In this figure, the net marginal abatement costs MAC - MCB comprise the gross marginal abatement costs MAC minus the domestic marginal co-benefits MCB that are regularly "private" from the developing country's point of view. $\mathrm{a}_{\mathrm{i}}{ }^{*}$ stands for the "business-as-usual" abatement level of country $i$, which is assumed to represent the abatement level that a "rational" developing country would choose voluntarily, i.e. where the marginal mitigation benefits $\mathrm{MB}_{\mathrm{i}}$ enjoyed by developing country $\mathrm{i}$ are equal to the marginal net abatement cost $\mathrm{MAC}-\mathrm{MCB}$ for this country. This is the abatement level maximizing domestic welfare.

The dotted triangle depicts the domestic net costs of attaining the "business-as-usual" level (or baseline) from the perspective of the developing country.

The abatement level a* is the globally optimal abatement level of country i, i.e. the level where the positive effects of country i's abatement efforts on other countries are taken into account and towards which the GEF transfer scheme intends to raise the abatement in country i. It is located where the global public marginal benefits $\mathrm{GPMB}_{\mathrm{i}+\mathrm{R}}$ of $\mathrm{GHG}$ abatement are equal to the net marginal abatement costs $\mathrm{MAC}-\mathrm{MCB}$ for the developing country.

The area $\mathrm{ABCD}$ (dashed area) stands for the net-incremental-cost transfer payments required to attain the optimum $\mathrm{a}^{*}$. Here the scheme nets out domestic co-benefits. In contrast, the larger area A'BCD' $=\mathrm{ABCD}+\mathrm{A}^{\prime} \mathrm{ADD}$ ' (comprising the dashed and checkered areas and the small monochromatic light grey triangle) represents the gross-incrementalcost transfer payment that is needed to attain the abatement level $\mathrm{a}^{*}$. The GIC scheme does not net out the domestic co-benefits represented by area A'ADD'.

These transfers only are based on the additional domestic abatement costs (net or gross) so that they are independent of the host country i's additional net primary climate benefits ABCC' enjoyed from the increase of the GHG abatement level from $\mathrm{a}_{\mathrm{i}}^{*}$ to $\mathrm{a}^{*}$. While ABCC' is the net benefit that the host country enjoys under the NIC scheme the respective net benefits in a GIC scheme are augmented by A'ADD' so that country $\mathrm{i}$ in total gains ABCC' + A'ADD'.

The figure clearly shows that the NIC concept leads to more cost-effectiveness: Given limited funds for climate transfers, the use of the method reimbursing only the NIC would reduce the transfer to country $i$. This would in the end allow to bring about a higher global level of climate change mitigation as the funds saved could be spent elsewhere to induce additional abatement activity. Under both the GIC and NIC scheme, the global community would enjoy a net welfare gain of the triangle ADF from increased climate protection in country $i$, but as the GIC scheme requires higher transfers of funds which are then lost for supporting climate protection elsewhere, the developed countries financing the GEF would be better off with the NIC scheme. This clearly shows that a distributional conflict between the donor and the recipient country exists that tends to be the more severe the higher the recipient's private co-benefits are.

However, despite these advantages with regard to climate protection the NIC concept raised objections because of its one-sided distributional implications in favour of the rich developed countries. It has been argued that surpluses of incremental actions in the recipient country should be shared between donor and recipient countries of GEF funds and "not appropriated fully by the global community through the net incremental cost principle" (King, 1993, p. 27). Yet, as explained above also the NIC concept benefits the host country as it raises this country's benefits by an amount reflected by area $\mathrm{ABCC}$. 
Pearce (1995, p. 169) stresses that sustainability goals and the need to foster cooperation should favour the GIC-concept. Interests of local communities should be carefully taken into account to raise their willingness to cooperate and net gains to local communities must be sustainable as otherwise project gains could be short-lived (GEF EO, 2006, p. 136). Therefore, it might be opportune to seek for a compromise, i.e. to apply a sharing rule, which is an intermediate between the NIC and the GIC rule. Indeed, as Pearce (2000) states, "[i]n practice, GEF tends to operate so that only some domestic ancillary benefits are deducted from the 'gross' incremental cost. Local environmental benefits may be computed but not deducted."

As both NIC and GIC refer to "incremental" costs, it was not without consequences for the inclusion of country-specific benefits that incremental cost calculations at the GEF came to an end in 2006. As assessments are made mostly at the end of the design of GEF projects and therefore have little impact on their design, it was argued that incrementality could only play an insignificant role as its exact size cannot be determined objectively ex ante. Actually, incrementality is achieved:

[...] through the initial negotiation that takes place between the GEF agents and the recipients in the definition of the baseline and the global environmental benefits that will be produced in the project (van den Berg, 2007, p. vii).

Another important reason for challenging GEF incremental cost calculations was the view (expressed by key people involved in GEF project design and review) that a clear distinction between local and global environmental benefits is largely artificial or even impossible to be reached (GEF EO, 2007, p. 7). Furthermore, there was much confusion of stakeholders about incremental cost concepts and procedures.

Due to the problems associated with the quantitative assessment of incremental cost, the GEF started to put greater emphasis on qualitative aspects of incrementality, which lead to the only vaguely specified concept of "incremental reasoning" (GEF IEO, 2018). This principle, which has meanwhile become the core principle underlying the GEF, "encapsulates the basic rationale for a project seeking GEF funding", i.e. the global environmental objectives and the GEF's contribution to the additional cost of projects required to pursue these objectives (GEF EO, 2007, p. 43).

By the incremental reasoning approach, negotiations taking place to decide on cofunding became more pragmatic regarding global, regional, national and local benefits. Through this changed perception of incrementality the partners put more effort in understanding the global benefits that are generated by a project.

As the attempts at making precise calculations of co-benefits and incremental cost calculations were skipped the focus on incremental reasoning significantly helped reduce transaction costs. As a consequence, purely subjective criteria gained the upper hand. In this vein, Broughton (2009, p. 69) points out that the abandoning of a "hard" norm in the shape of incremental-cost calculations and the transition to the "softer" way of assessing incrementality, "may not make the concept easier to understand or to apply within projects for those applicants searching for clarification" [3]. Furthermore, the softer norm may find less acceptance in countries paying international transfers as there may be more room for manoeuvre by developing countries during the negotiations (that take place between the GEF agents and the recipients of funds) aiming at appropriating additional rents at the expense of the donors. Yet, much depends on the bargaining power of involved agents as can be observed from the CDM example addressed in the next section.

Finally, it is worth mentioning that incremental reasoning does not only play a role for the GEF Trust Fund, but e.g. the Green Climate Fund also refers to it in its requirements for 
IJCCSM

$13,4 / 5$

funding proposals (GCF, 2019, p. 9). Yet, it is also argued by the GCF (2018, p. 5) that quantitative approaches allow a more precise and accurate assessment of incremental costs.

\section{The clean development mechanism, premiums and co-benefits}

Another international mechanism in the context of climate finance is the CDM. This mechanism under the Kyoto Protocol was - unlike the GEF - from the beginning designed with the dual aim of assisting developing countries in achieving SD and of helping developed countries in achieving compliance with their Kyoto commitments. The CDM allows governments or private entities of developed countries (having ratified the Protocol) to implement emission reduction projects in developing countries and to receive credit in the shape of "certified emission reductions" (CERs). These CERs can be counted against the developed countries' national reduction targets.

Hence, all countries should benefit from the mechanism: while the transfer payer will receive CERs, the transfer receiving developing country will obtain national SD benefits. These SD benefits are regularly - and yet quite broadly - classified into the three categories "environmental", "social" and "economic". However, in the context of the CDM under the Kyoto Protocol, there is a lack of a clear definition of SD and an absence of the requirement to monitor SD impacts. In the Marrakesh Accords, it was affirmed in 2001 (UNFCCC, 2002) that "it is the host Party's prerogative to confirm whether a CDM project activity assists it in achieving sustainable development". Due to the ambiguity of SD concepts and indicators, developing countries may get a strategic incentive to set rather low SD standards before bargaining starts to become a particularly attractive CDM investment location for foreign investors that are primarily interested in earning CERs. This provides other examples for strategically motivated pre-bargaining moves that have been considered in other contexts of international environmental economics (Buchholz and Konrad, 1994 and Beccherle and Tirole, 2011).

In the competition for CDM projects and financing, a "race to the bottom"-risk is pending (Sutter, 2003 and Olsen, 2007), which means that developing countries are willing to accept more and more projects with rather low co-benefits as they compete with other countries for international project funds.

Despite, in times of falling demand for CERs after 2011-2012 [4], i.e. when bargaining power on the supply side was decreasing, the "race to the bottom"-risk was reduced to some extent, as the relatively (to the demand) high supply "enabled buyers to differentiate between CERs of different characteristics" (Michaelowa et al., 2020a, p. 54). Possibly the developments on the CERs market were accompanied by investors' rising attention for public concern about SD and purchasing CERs from projects with a high SD-content was part of a marketing strategy partly in the sense of "green-washing". It seems that there is still much scope for research in this context.

Concerning the SD-related differences, Sutter and Parreño (2007, p. 89) have been among the first to propose a specific "premium market" for CERs from those projects that strongly contribute to SD - hoping that this might raise the share of such projects in the global carbon market. According to Sutter (2003, p. 202), such premium CERs could be attractive for purchasers as they might help to prevent reputation losses that may arise from financing unsustainable CDM projects. To establish such markets, labels for certain CERs had to be created that indicate a higher level of SD benefits associated with these CERs. Among those labels are the "Gold Standard" that has issued more than 98.4 million carbon credits in 2018 (Willers and Cima, 2019) [5].

However, GHG emission reductions by projects with a higher mandatory SD component tend to be more expensive, which is also due to now necessary thorough project evaluation 
and labelling. Especially if small projects are concerned, the transaction costs for receiving a label may become prohibitively high. Mechanisms like the Gold Standard need to carefully balance transparency, accountability and transaction costs (Robinson et al., 2016, p. 134). Transaction costs usurp at least a portion of the welfare gains that the private offsetting standards intend to bring about. Due to their higher cost relative to those of projects on regular CER markets, GHG abatement activities for a premium market tend not to be costeffective from a climate-change-mitigation point of view.

Furthermore, Olsen et al. (2019, p. 247) stress, "sustainability labels have never climate finance developed beyond a small niche in the compliance market and attract only a small share of the carbon finance available”. Hence, the voluntary nature of the premium scheme seems to be no appropriate blueprint for future schemes under the Paris Agreement. Instead, some liability would be required to raise the market penetration of projects with higher co-benefits.

If a future scheme stipulates minimum sustainability standards for SDM projects so that projects with low co-benefit levels are definitely banned from the trading scheme, then the marginal abatement cost curve obviously tends to rise. The effects of a shift towards more sustainable projects on the outcome of a CDM transfer scheme is illustrated in Figure 2, which resembles Figure 1, but in which the increase of marginal abatement costs for projects yielding higher local sustainability benefits is reflected by a marginal cost mark-up MCM.

As in Figure 1, the MAC curve (as a reference case) reflects the marginal abatement costs for the mitigation activities in country i if no minimum standards were established. Before the introduction of an obligatory premium component into the CDM scheme, the host country is supposed to supply the CERs at MAC.

The aggregate curve MAC + MCM represents the marginal abatement costs when a (higher) minimum sustainable-development standard is required for CDM projects, and hence different mitigation projects - with higher co-benefits - are supplied by the developing countries on the CER market. Due to the cost mark-up, the purchasers then are required to pay the higher CERs price corresponding to $\mathrm{MAC}+\mathrm{MCM}$, what buyers only did voluntarily on premium markets in the past. According to Lou (2020), the quality control indicators (like the Gold Standard), which were used to qualify such projects with higher SD standards, had a significant effect on the prices of CERs leading to a price premium in the range of $\$ 1.13 / \mathrm{tCO} 2 \mathrm{e}$ to $\$ 4.2 / \mathrm{tCO} 2 \mathrm{e}$ in 2018.

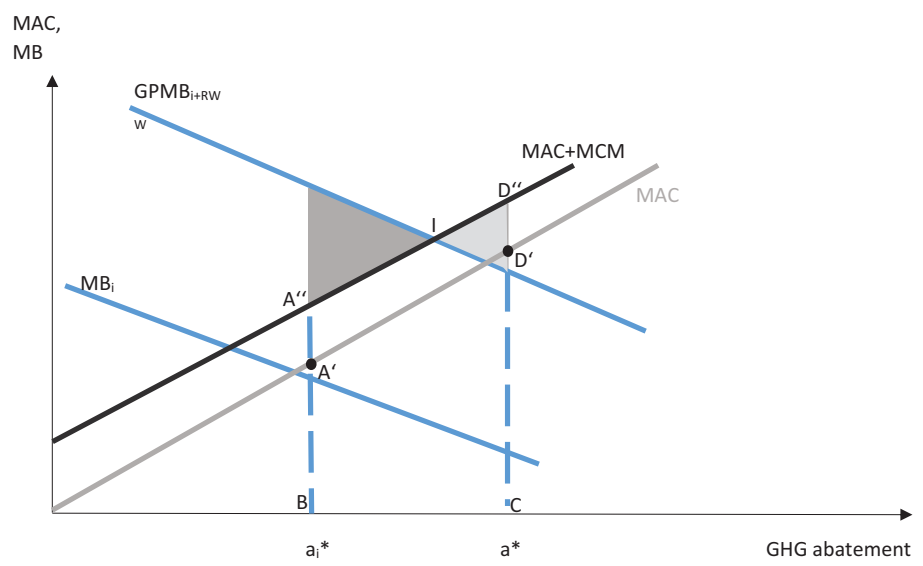

Figure 2. Illustration of the

CDM when a minimum level of local co-effects is obligatory 
IJCCSM

$13,4 / 5$

556
The subsequent analysis is now divided in two steps: In a first step, we purely consider the effect of increased marginal abatement cost on climate change mitigation. In a second step, we evaluate the scheme taking into account the co-benefits enjoyed by the country hosting the CDM project.

To make schemes comparable, we refer to the same abatement levels $\mathrm{a}^{*}$ and $\mathrm{a}_{\mathrm{i}}{ }^{*}$ considered in Figure 1. As we will argue below, $\mathrm{a}^{*}$ is, however, unlikely to be attained under the premium CDM scheme.

\subsection{Step 1}

If under the CDM scheme with SD standards the GHG abatement level a* could be reached, then the international transfer payments on the premium market are represented by the area A"BCD", i.e. the area below the line depicting MAC + MCM in the range between $\mathrm{a}_{\mathrm{i}}{ }^{*}$ and $\mathrm{a}$ * Clearly A"BCD" > A'BCD' holds [6]. Hence, the CDM transfers via the premium market that are required to attain $\mathrm{a}^{*}$ are higher than the transfers under the GEF schemes.

The abatement level a*, which is the efficient abatement level when the cheapest mitigation options in country $i$ are chosen, now appears inefficiently high as costs of eligible $\mathrm{CDM}$ projects have increased. In a CDM system with minimum SD standards then the point of intersection I between the GPMB and the MAC+MCM curve would have to be considered as optimal which, however, would lead to lower abatement efforts in country i as compared to $\mathrm{a}^{*}$.

Reaching the reference abatement level $\mathrm{a}^{*}$ through this scheme with minimum SD standards not only increases the payments by the industrialized countries but also may reduce global welfare. This is avoided with certainty if in Figure 2 the dark grey triangle, which displays the excess of global public benefits over the international payments, is larger than the light grey triangle that stands for the excess of the transfers over the global benefits.

If marginal costs of projects further rise due to higher SD requirements, in Figure 2, the marginal abatement cost curve MAC + MCM shifts upwards so that the dark grey triangle shrinks and the light grey triangle is enlarged, and thus the cost-effectiveness of GHG mitigation further declines. While this implies higher costs for industrialized countries, the system remains profitable for developing countries, which enjoy higher co-benefit levels free

of charge.

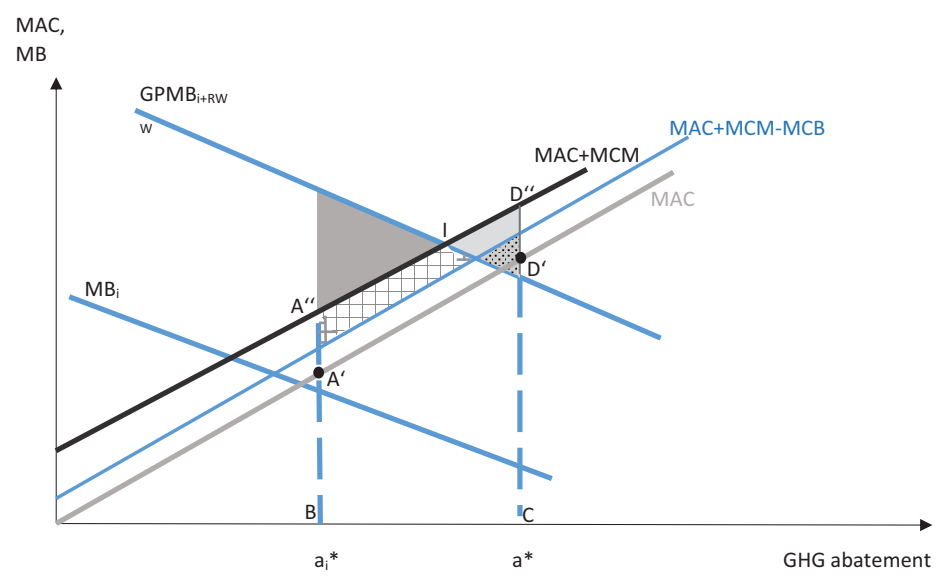

\section{Figure 3.}

Inefficient mitigation and SD

improvements 


\subsection{Step 2}

International

For a complete welfare comparison, the light grey triangle has to be adjusted by country i's additional private co-benefits when its abatement stays at $\mathrm{a}^{*}$. This is shown in Figure 3 where the additionally generated marginal co-benefits MCB in country i are included. The dark grey triangle then is expanded by the chequered area left to the point of intersection between GPMB and MAC $+\mathrm{MCM}-\mathrm{MCB}$, and the light grey triangle shrinks to the dotted area right to this point.

If in this case the mark-up MCM rises more strongly than the additional marginal coclimate finance benefits $\mathrm{MCB}$, i.e. $\mathrm{MCM}>\mathrm{MCB}$, the net abatement cost curve MAC + MCM - MCB is located above the MAC curve. Additionally to the inefficiency in climate change mitigation then there is inefficiency through rising co-benefits as these additional co-benefits are generating costs that exceeds these benefits.

In a laissez-faire system, the developing country would not even abate up to level $\mathrm{a}_{\mathrm{i}}^{*}$ if this abatement has to be generated by premium projects for which MCM $>$ MCB holds, as at this abatement level country i's marginal benefits are below net marginal cost, i.e. $\mathrm{MB}_{\mathrm{i}}<\mathrm{MAC}+$ MCM - MCB. However, as domestic abatement can be conducted by non-premium projects and as industrialized countries pay the higher cost of premium projects, the premium scheme remains attractive. The developing country simply enjoys higher levels of co-benefits.

Of course, it could be the case that MCB $>$ MCM instead so that the MAC + MCM MCB curve lies below the MAC curve, and thus provision at a* may be efficient when additional co-benefits are taken into account. Then the implementation of a premium scheme could be justified from the viewpoint of welfare maximization.

There is another important aspect that has to be taken into account for the analysis of premium schemes in general: as potential purchasers of CERs will not be willing to pay any price it can be expected that high premiums will have a negative effect on the demand of CDM projects and consequently on global climate protection and welfare. The host country's abatement activity that is aimed at by the donor country may fall below $a^{*}$. This implies that the transfer scheme with mandatory premium prices might not bring about the globally efficient GHG abatement level that would be achieved by a scheme without higher SD requirements. However, while projects with low co-benefits would not be eligible under a premium scheme, these cheaper abatement options could be included in the nationally determined contributions (NDCs) of developing countries. Then the overall abatement that is induced by the combination of the transfer scheme and the NDCs could become higher.

That the CDM and the NDCs of developing countries exerted mutual influence could already be observed in the past. So high numbers of CDM projects in a developing country tended to have an adverse effect on mitigation efforts declared in the NDCs (Stahlke, 2020) of this country so that the transfer mechanism created disincentives for more ambitious climate action in host countries of CDM projects. In the future, this disincentive could be reduced if high standards for projects supported by international transfers leave cheaper options for inclusion in the NDCs.

Despite the concerns regarding its overall cost-effectiveness of GHG abatement, premium prices have been getting new prominence in the context of the Paris Agreement. What has to be observed in this context by political decision makers will now be discussed.

\section{Cooperative approaches in accordance with Article 6 of the Paris Agreement}

Article 6 of the Paris Agreement postulates the necessity of international cooperative approaches for climate protection and, in this context, the support of SD. According to Articles 6.2-6.3 Parties can cooperate directly with one another on a voluntary basis. This 
IJCCSM

$13,4 / 5$

renders possible the implementation of emission reduction measures in one country and the transfer of associated emission reduction "credits" to another country so that the reductions can be counted towards the latter country's NDC. Furthermore, it allows to link emissionstrading schemes of two or more countries. Articles 6.4-6.7, which are of particular importance in the context of this paper, establish mechanisms that both contribute to the mitigation of greenhouse gas emissions and mainly for distributional reasons, to support SD in poorer countries. Those mechanisms may share similarities with the CDM (Michaelowa et al., 2019a). In Articles 6.8-6.9, the importance of non-market approaches is recognized, but it still has to be specified how these approaches are to be executed and as is stated on a UNFCCC (2020) website, the non-market approaches mechanism can presently "be anything and everything, provided it's not market-based".

The consideration of co-effects made above will help to inform decision makers about the various concepts, their merits and weaknesses, relevant in the context of local sustainability effects. As already stated in the Introduction, aiming at the same time at two different goals naturally might cause a conflict. The efficiency goal is reflected by the sub-criteria "costeffectiveness concerning mitigation" and "(low) transaction cost" of a transfer scheme. From the analysis above we know that the cost-effectiveness of GHG mitigation is highest in the GEF-NIC scheme as this is based exclusively on global benefit orientation while premium CDM-like schemes perform poorest in this regard. Concerning transaction cost, the GEF-GIC scheme is advantageous as it does not net out co-benefits and just disburses GICs. Schemes based on incremental reasoning could be a compromise in the context of schemes requiring a kind of evaluation of co-benefits, but the criteria for executing incremental reasoning tend to be quite arbitrary.

Following the distributional goal clearly leads to a conflict between "rewards to developing countries" on the one hand and "public acceptance in industrialized countries" on the other. Through high transfers flowing to developing countries, ethical concerns are well addressed as it is signalled that the poorer countries are not exploited via the transfer scheme. Yet, this may imply higher transfer levels for combating global warming, and therefore conflicts not only with cost-effectiveness in climate protection, and hence with the efficiency goal but also with public acceptance in industrialized countries as the distributional advantages in developing countries would be at the expense of the donors. Concerning the criterion "rewards to developing countries" premium CDM-like schemes have their merits, while the GEF-NIC scheme performs poorest. Public acceptance in economically developed countries tends to be highest for the GEF-NIC scheme as it costeffectively raises global climate protection. Yet, involved high transaction costs may impair this attractiveness from industrialized countries' point of view. According to our analysis, premium CDM-like schemes would be least attractive for economically developed countries, but as purchasers are free to refrain from purchasing CERs if their prices increase, political opposition may be moderate.

The discussion about the designing futures schemes under Article 6 of the Paris Agreement has gained much momentum in the scientific literature. In this context - and in accordance with the central argument of this paper - special attention has been given to the integration of SD goals in a transfer scheme.

Olsen et al. (2018, p. 393) warn in their discussion of lessons learnt from the CDM that:

[...] there is a great risk of repeating the 'race to the bottom' known from the CDM, where the prerogative for host countries to approve SD has resulted in weak national SD criteria.

While this race to the bottom would thwart the distributional goals efficiency of climate change mitigation might be promoted to some extent. But note that positive allocative 
effects may also be triggered via the enhancement of perceived fairness in the developing countries [7], which spurs their willingness to participate actively in climate policy (Rübbelke, 2011 and Pittel and Rübbelke, 2013).

To foster distributional goals some scientists highlight the role private offsetting standards (like the "Gold Standard") may play in future international climate policy and explicitly suggest applying premium prices to overcome the problem of the race to the bottom. In addition, Blum and Lövbrand (2019) express the view that private standard setters fill "perceived legitimacy gaps" of public governance mechanisms. This positive view of private standards is supported by the empirical finding that many buyers of CERs are willing to pay a price premium. According to Parnphumeesup and Kerr (2015), charity groups and governments are much more willing to pay a premium than commercial buyers. Purchasers at premium prices do this by either altruistic motives or because of a higher quality of their investments, which might result from a higher degree of participation and cooperation of local stakeholders. Against this background, Hultman et al. (2019) suggest that it may become important to encourage more purchasers to act on the premium market in the future. To reduce transaction costs Olsen et al. (2019) endorse an approach which uses qualitative characteristics of a project to assess its expected SD benefits and to rank various projects in this way. As these qualitative data are more easily accessible than quantitative ones the approval of projects can be facilitated and accelerated.

Olsen et al. (2019) even suggest to link the Paris Agreement and the 2030 Agenda for SDGs in the future by using the SDG global indicator framework in evaluating SD aspects of mitigation activities. There is already a Gold Standard called "Gold Standard for the Global Goals" that quantifies and verifies impacts of climate initiatives towards multiple SDGs [8]. This link between SDGs and climate protection could provide new opportunities for industrialized countries. The updated National Sustainable Development Strategy of Germany (The Federal Government, 2018, p. 8), for example, sets out the importance of the 2030 Agenda for SDGs for curbing international movements of refugees and migrants. European countries, hence may strongly benefit from SD in Northern Africa, for example, but to a lesser extent from such a development in Central America. This means that some components of SD are not exclusively private for the hosts of climate change mitigation projects, but spillovers spread transcontinentally or even globally [9].

\section{Conclusions}

The discussion on the treatment of co-benefits in climate finance has undergone considerable changes in the past decades: Applying tools to raise local SD effects of climate protection projects in developing countries was not seriously taken into consideration in the early years of the GEF. In the early and mid-1990s, the discussion instead was mainly about global benefits and attaining efficiency in greenhouse gas abatement. Consequently, the preference prevailed to reduce the transfers at least by a part of the domestic co-benefits in the host country of the project.

Meanwhile, however, the application of a premium-price mechanism, which rewards the host countries twice, i.e. through additional climate protection benefits and through domestic sustainability co-benefits, is frequently proposed. Yet, making premium prices a prerequisite for activities under Article 6.4 of the Paris Agreement would raise the costs of such desired activities for all purchasers, and thus reduce their demand on the certificate market, which could undermine the functionality of mechanisms under Article 6 of the Paris Agreements. Opposition against premium prices thus is warranted when the fight against global warming and cost-effectiveness in GHG abatement is paramount. In the longer run, 
IJCCSM

$13,4 / 5$

increased efficiency could also mitigate the distributional conflicts between the rich and the poor countries, especially as the developing countries benefit much from climate protection.

Other participants in the global climate dialogue, however, consider cooperative approaches under Article 6 as some kind of indulgence trade motivated by some morally grounded "joy of giving" towards the developing countries. The deep problem with this view, however, is that the objectives of international climate policy are obfuscated and that, as a consequence, climate change as the main threat may come out of sight. Putting emphasis on distributional motives goes hand in hand with a preference for softer norms of assessing co-benefits. In many cases, such softer norms may help lowering transaction costs (e.g. through saving the expenses for consultancies) and accelerating the pace at which abatement projects can be launched in developing countries. Moreover, they may seem attractive for purely pragmatic reasons, as some co-benefits are hard to quantify, like e.g. those benefits associated with gender aspects. Yet, this vagueness of the criteria creates much scope for rent-seeking activities and jeopardizes the effectiveness and efficiency of global climate protection.

In any rational discussion on international transfer mechanism as an important part of global climate policy, one has to keep in mind that "climate finance and development aid are defined by different objectives and should be treated therefore as distinct entities" (Peterson and Skovgaard, 2019, p. 72). One should therefore follow the Tinbergen rule stated in the Introduction and avoid an overburdening of climate policy with the expectation to become an overarching cure for multiple problems. This means that the promotion of local SD of developing countries and promoting global equity should be addressed separately and be reserved for development aid.

\section{Notes}

1. Presently, in the period 2018-2022, the focal areas are climate change, biodiversity, land degradation, chemical and waste and international waters.

2. The Fund that was established on the eve of the 1992 Rio Earth Summit.

3. This holds the more as incremental reasoning was not defined by the GEF when it was introduced as the core principle. According to GEF EO (2007), "[p]rocedurally, it implies logical argumentation and case-based reasoning, which has implications when ascertaining the basic rationale for GEF projects."

4. On the development of international carbon markets in the recent two decades, see Michaelowa et al. (2019b).

5. On this and other standards like the Climate, Community \& Biodiversity Standard and the Social Carbon Standard see, e.g. Michaelowa et al. (2019a, 2019b, 2019c) and Michaelowa et al. (2020a).

6. A'BCD' reflects the maximum transfers by the GEF, which are the gross incremental cost transfers.

7. There are several studies addressing international climate finance and its influence on fairness or justice, e.g. Pickering et al. (2017).

8. See https://www.goldstandard.org/articles/gold-standard-global-goals

9. A distinction between direct and final or ultimate impact (van den Berg, 2011, p. 413) seems to be relevant in this context.

\section{References}

Beccherle, J. and Tirole, J. (2011), "Regional initiatives and the cost of delaying binding climate change agreements", Journal of Public Economics, Vol. 95 Nos. 11/12, pp. 1339-1348. 
Blum, M. and Lövbrand, E. (2019), "The return of carbon offsetting? The discursive legitimation of new market arrangements in the Paris climate regime", Earth System Governance, Vol. 2, 100028.

Broughton, E. (2009), "The Global Environment Facility: Managing the Transition”, Ifri, Health and Environment Reports, No. 3, Paris.

Buchholz, W. and Konrad, K. (1994), "Global environmental problems and the strategic choice of technology”, Journal of Economics, Vol. 60 No. 3, pp. 299-321.

Buchholz, W., Markandya, A., Rübbelke, D. and Vögele, S. (2020), Ancillary Benefits of Climate Policy New Theoretical Developments and Empirical Findings, Springer, Cham.

Campagnolo, L. and De Cian, E. (2020), "Can the paris agreement support achieving the sustainable development goals?", in Buchholz, W., Markandya, A., Rübbelke, D. and Vögele, S. (Eds), Ancillary Benefits of Climate Policy, Springer, Cham, pp. 15-50.

Coase, R. (1960), "The problem of social cost”, The Journal of Law and Economics, Vol. 3, pp. 1-44.

Fankhauser, S. and Pearce, D. (2014), "Financing for sustainable development", in Atkinson, G., Dietz, S., Neumayer, E. and Agarwala, M. (Eds), Handbook of Sustainable Development, Edward Elgar Publishing, Cheltenham, pp. 446-459.

GCF (2018), "Incremental and full cost calculation methodology”, GCF/B.21/03, Incheon.

GCF (2019), "Review of the initial investment framework: matters related to incremental and full cost calculation methodology and policies on co-financing and concessionality", GCF/B.23/19, Incheon.

GEF (2007), "Operational guidelines for the application of the incremental cost principle", GEF Policy Paper, Washington, DC.

GEF EO (2006), "The Role of Local Benefits in Global Environmental Programs", Evaluation Report No. 30, Washington, DC.

GEF EO (2007), "Evaluation of Incremental Cost Assessment”, Evaluation Report No. 34, Washington, DC.

GEF IEO (2018), “An evaluative approach to assessing GEF's additionality”, GEF/ME/C.55/inf. 01, Washington, DC.

Góes, M.D.F.B., Andrade, J.C.S., Jabbour, C.J.C. and Silva, M.S. (2021), "Wind power projects in Brazil: challenges and opportunities increasing co-benefits and implications for climate and energy policies", Environment, Development and Sustainability, pp. 1-27.

Hultman, N.E., Lou, J. and Hutton, S. (2019), "A review of community co-benefits of the clean development mechanism (CDM)", Environmental Research Letters, Vol. 15 No. 5, p. 53002.

IISD (2019), "GEF bulletin”, International Institute for Sustainable Development, Vol. 192 No. 23, available at: https://enb.iisd.org/download/pdf/sd/enbplus192num23e.pdf

Kaul, I. and Conceição, P. (2006), "The changes under way: financing global challenges through international cooperation behind and beyond borders", in Kaul, I. and Conceição, P. (Eds), The New Public Finance - Responding to Global Challenges, Oxford University Press, New York, NY and Oxford, pp. 28-70.

King, K. (1993), "The incremental costs of global environmental benefits”, Working Paper No. 5, Global Environment Facility, Washington, DC.

King, K. (2006), "Compensating countries for the provision of global public services: the tool of incremental costs", in Kaul, I. and Conceição, P. (Eds), The New Public Finance - Responding to Global Challenges, Oxford University Press, New York, NY and Oxford, pp. 371-388.

Lang, S., Blum, M. and Leipold, S. (2019), "What future for the voluntary carbon offset market after Paris? An explorative study based on the discursive agency approach", Climate Policy, Vol. 19 No. 4, pp. 414-426.

Lou, J. (2020), "Integrating sustainable development goals into climate finance projects: assessing the market impact of co-benefits from carbon offsets", Doctoral dissertation, University of Maryland, College Park. 
IJCCSM $13,4 / 5$

Markandya, A., Galarraga, I. and Rübbelke, D. (2017), Climate Finance: Theory and Practice, World Scientific, Singapore.

Michaelowa, A., Espelage, A. and Müller, B. (2019a), Negotiating Cooperation under Article 6 of the Paris Agreement, Perspectives, Freiburg.

Michaelowa, A., Shishlov, I. and Brescia, D. (2019b), "Evolution of international carbon markets: lessons for the Paris agreement", Wiley Interdisciplinary Reviews: Climate Change, Vol. 10 No. 6, p. e613.

Michaelowa, A., Shishlov, I., Hoch, S., Bofill, P. and Espelage, A. (2019c), Overview and Comparison of Existing Carbon Crediting Schemes, Perspectives, Freiburg.

Michaelowa, A., Espelage, A. and Hoch, S. (2020a), "Co-benefits under the market mechanisms of the Paris agreement”, in Buchholz, W., Markandya, A., Rübbelke, D. and Vögele, S. (Eds), Ancillary Benefits of Climate Policy, Springer, Cham, pp. 51-67.

Michaelowa, A., Brescia, D., Wohlgemuth, N., Galt, H., Espelage, A. and Moreno, L. (2020b), CDM Method Transformation: updating and Transforming CDM Methods for Use in an Article 6 Context, Perspectives, Freiburg.

Mori-Clement, Y. (2019), "Impacts of CDM projects on sustainable development: improving living standards across Brazilian municipalities?", World Development, Vol. 113, pp. 222-236.

Nemet, G.F., Holloway, T. and Meier, P. (2010), "Implications of incorporating air-quality co-benefits into climate change policymaking”, Environmental Research Letters, Vol. 5 No. 1, p. 14007.

Olsen, K.H. (2007), "The clean development mechanism's contribution to sustainable development: a review of the literature", Climatic Change, Vol. 84 No. 1, pp. 59-73.

Olsen, K.H., Arens, C. and Mersmann, F. (2018), "Learning from CDM SD tool experience for article 6.4 of the Paris agreement", Climate Policy, Vol. 18 No. 4, pp. 383-395.

Olsen, K.H., Bakhtiari, F., Duggal, V.K. and Fenhann, J.V. (2019), "Sustainability labelling as a tool for reporting the sustainable development impacts of climate actions relevant to article 6 of the Paris agreement", International Environmental Agreements: Politics, Law and Economics, Vol. 19 No. 2, pp. 225-251.

Parnphumeesup, P. and Kerr, S.A. (2015), "Willingness to pay for gold standard carbon credits”, Energy Sources, Part B: Economics, Planning and Policy, Vol. 10 No. 4, pp. 412-417.

Pearce, D. (1995), Blueprint 4: Capturing Global Environmental Value, Earthscan, London.

Pearce, D. (2000), "Policy framework for the ancillary benefits of climate change policies", in Ancillary Benefits and Costs of Greenhouse Gas Mitigation, OECD, Paris, pp. 517-560.

Pearce, D. (2004), "Environmental market creation: saviour or oversell?”, Portuguese Economic Journal, Vol. 3 No. 2, pp. 115-144.

Pearce, D. (2007), “Do we really care about biodiversity?", Environmental and Resource Economics, Vol. 37 No. 1, pp. 313-333.

Peterson, L. and Skovgaard, J. (2019), "Bureaucratic politics and the allocation of climate finance", World Development, Vol. 117, pp. 72-97.

Pickering, J., Betzold, C. and Skovgaard, J. (2017), "Special issue: managing fragmentation and complexity in the emerging system of international climate finance", International Environmental Agreements: Politics, Law and Economics, Vol. 17 No. 1, pp. 1-16.

Pittel, K. and Rübbelke, D. (2013), "International climate finance and its influence on fairness and policy", The World Economy, Vol. 36 No. 4, pp. 419-436.

Rive, N. and Rübbelke, D. (2010), “International environmental policy and poverty alleviation”, Review of World Economics, Vol. 146 No. 3, pp. 515-543.

Robinson, C.J., Renwick, A.R., May, T., Gerrard, E., Foley, R., Battaglia, M., Possingham, H., Griggs, D. and Walker, D. (2016), "Indigenous benefits and carbon offset schemes: an Australian case study”, Environmental Science and Policy, Vol. 56, pp. 129-134. 
Rübbelke, D. (2011), "International support of climate change policies in developing countries: strategic, moral and fairness aspects", Ecological Economics, Vol. 70 No. 8, pp. 1470-1480.

Shrivastava, M.K. and Bhaduri, S. (2019), "Market-based mechanism and 'climate justice': reframing the debate for a way forward", International Environmental Agreements: Politics, Law and Economics, Vol. 19 Nos. 4/5, pp. 497-513.

Stahlke, T. (2020), “The impact of the clean development mechanism on developing countries' commitment to mitigate climate change and its implications for the future", Mitigation and Adaptation Strategies for Global Change, Vol. 25 No. 1, pp. 107-125.

Stahlke, T., Some, S., Mukherjee, V. and Rübbelke, D. (2021), “Co-Benefits of CDM's renewable energy projects in India and their contribution to SDGs", in Leal Filho, W., Luetz, J. and Ayal, D. (Eds), Handbook of Climate Change Management, Springer, Cham, pp. 1-21.

Sutter, C. (2003), Sustainability Check up for CDM Projects: How to Assess the Sustainability of International Projects under the Kyoto Protocol, ETH Zurich, Zurich.

Sutter, C. and Parreño, J.C. (2007), "Does the current clean development mechanism (CDM) deliver its sustainable development claim? An analysis of officially registered CDM projects", Climatic Change, Vol. 84 No. 1, pp. 75-90.

The Federal Government (2018), "Deutsche Nachhaltigkeitsstrategie”, Aktualisierung 2018, Berlin.

Ugochukwu, B. (2020), "Challenges of integrating SDGs in market-based climate mitigation projects under the Paris agreement", McGill International Journal of Sustainable Development Law and Policy, Vol. 16 No. 1, pp. 115-135.

UNFCCC (2002), "Report of the conference of the parties on its seventh session", FCCC/CP/2001/13/ Add.2, Decision 17/CP.7, available at: https://undocs.org/FCCC/CP/2001/13/Add.2

UNFCCC (2020), "What are market and non-market mechanisms?", available at: https://unfccc.int/ topics/what-are-market-and-non-market-mechanisms (accessed 02 June 2020).

Van den Berg, R. (2007), "Foreword", in Global Environment Facility Evaluation Office, Evaluation of Incremental Cost Assessment, Evaluation Report No. 34, Washington, DC.

Van den Berg, R. (2011), "Evaluation in the context of global public goods", Evaluation, Vol. 17 No. 4, pp. 405-415.

West, J.J., Smith, S.J., Silva, R.A., Naik, V., Zhang, Y., Adelman, Z., Fry, M.M., Anenberg, S., Horowitz, L. W. and Lamarque, J.F. (2013), "Co-benefits of mitigating global greenhouse gas emissions for future air quality and human health”, Nature Climate Change, Vol. 3 No. 10, pp. 885-889.

Willers, C. and Cima, E. (2019), "Gold standard - market report 2018”, available at: www.goldstandard. org/sites/default/files/market_report_2018.pdf

\section{Corresponding author}

Dirk Rübbelke can be contacted at: dirk.ruebbelke@vwl.tu-freiberg.de

For instructions on how to order reprints of this article, please visit our website:

www.emeraldgrouppublishing.com/licensing/reprints.htm

Or contact us for further details: permissions@emeraldinsight.com 